\title{
Analysis of Direct Torque Control with Space Vector Modulation for Synchronous Reluctance Motor Motion Control Applications and a Comparison with Other Torque-Control Algorithms
}

Research Article

Tibor Vajsz, László Számel, Árpád Handler

Department of Electric Power Engineering, Faculty of Electrical Engineering and

Informatics, Budapest University of Technology and Economics, $\mathrm{H}-1111$,

Egry J. Street 18, Budapest, Hungary

Received December 21, 2018; Accepted April 2, 2019

Abstract: Motion control is facing an increasing popularity in the present research activities. Owing to the expected wide spreading of motion control applications, it can be predicted that the advancements in the field of electric motor drives will have a high level of influence on the new results in the field of motion control. The synchronous reluctance motor drives mean an excellent and yet cost-effective solution for actuators in motion control applications. In this article, the direct torque control with space vector modulation is analysed as a possible candidate for synchronous reluctance motor motion control applications. Its torque-control performance is investigated as a function of torque-control sample time, and a comparison of the torque ripples is made with other torque-control algorithms by an FFT analysis.

Keywords: synchronous reluctance motor $\bullet$ electric drive $\bullet$ direct torque control $\bullet$ space vector modulation $\bullet$ frequency converter $\bullet$ motion control $\bullet$ current vector control $\bullet$ industrial drives

\section{Introduction}

The field of motion control is facing an increasing popularity in the present research activities. Owing to the expected wide spreading of motion control applications, it can be anticipated that this field will stay in the centre of interest in the future. The vast majority of the motion control applications use electric motors as actuators. Therefore, it can be predicted that the development in the field of electric motor drives will have a high level of impact on the new results in the field of motion control applications.

Synchronous reluctance motor drives are also receiving growing attention from electric motor drive researchers and experts due to their simple, rugged and cheap construction; high power density and high efficiency. These are all important aspects in the case of motion control applications. Apart from the motor construction, the utilized torquecontrol algorithm also has an essential effect on the main features of an electric motor drive system. Therefore, in this article, the direct torque control with space vector modulation (DTC-SVM) is analysed as a potential candidate for synchronous reluctance motor motion control applications. Its torque-control performance is investigated in the function of torque-control sample time, and a comparison is made with other torque-control algorithms (direct torque control (DTC) and hysteresis current vector control) in means of torque ripples by making an FFT analysis. 


\section{Direct Torque Control with Space Vector Modulation}

The basic principle of DTC-SVM is that the electromagnetic torque is controlled by regulating the load angle and the amplitude of the stator flux vector. The exact relationship for the electromagnetic torque is

$$
m=\frac{3}{4} p\left(\frac{1}{L_{q}}-\frac{1}{L_{d}}\right) \Psi^{2} \sin (2 \delta),
$$

where $m$ is the electromagnetic torque, $p$ is the number of pole pairs, $L_{d}$ and $L_{q}$ are the direct- and the quadratureaxis synchronous inductances, $\psi$ is the amplitude of the stator flux vector and $\delta$ is the load angle (the angle between the stator flux vector and the $d$-axis). This means that the basic principle is the same as in the case of the DTC. For a detailed description of the DTC, see Vajsz et al. (2019).

However, in contrast to the DTC, the DTC-SVM uses continuous-output-type controllers and space vector modulation (SVM) instead of hysteresis controllers and a switching table. Fig. 1 shows the block diagram of the DTC-SVM.

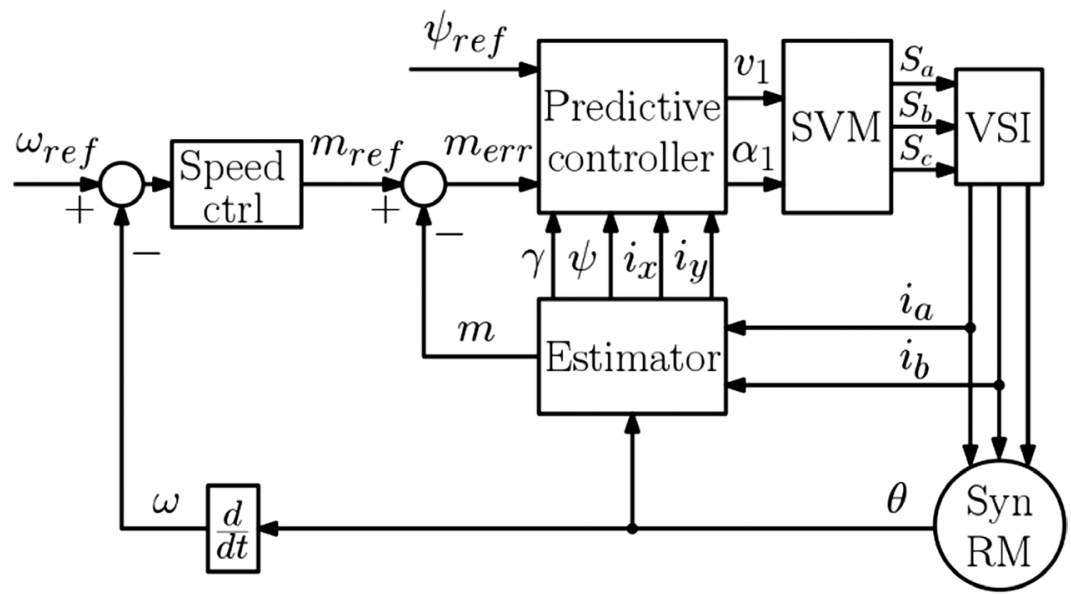

Fig. 1. Direct torque control with space vector modulation (DTC-SVM) (Swierczynski and Kazmierkowski, 2002; Swierczynski et al., 2002; Vajsz et al., 2017)

According to Fig. 1, an estimator is used in order to compute the state variables required by the predictive controller. These variables are the real- and the imaginary-axis components of the stator current vector in the two-phase stationary coordinate-system $\left(i_{x}\right.$ and $\left.i_{y}\right), \psi$ and the position of the stator flux vector in the $x-y$ coordinatesystem $(\gamma)$. Based on these signals and the torque-error signal $\left(m_{\mathrm{err}}\right)$ and the stator flux amplitude reference signal $\left(\psi_{\text {ref }}\right)$, the predictive controller synthesizes the stator voltage vector reference (its amplitude is $v_{1}$ and its angle is $\alpha_{1}$ in the $x-y$ coordinate system) that is fed to the space vector modulator (SVM).

After the transformation of the phase currents to the $d-q$ coordinate system, the real- and the imaginary-axis components of the stator flux vector $\left(\psi_{d}\right.$ and $\left.\psi_{q}\right)$ are computed using the following equations:

$$
\begin{aligned}
& \Psi_{d}=L_{d} i_{d} \\
& \Psi_{q}=L_{q} i_{q},
\end{aligned}
$$

where $i_{d}$ and $i_{q}$ are the direct- and the quadrature-axis components of the stator current vector. The electromagnetic torque is estimated in the following way:

$$
m=\frac{3}{2} p\left(L_{d}-L_{q}\right) i_{d} i_{q}
$$


Then $\psi_{d}+j \psi_{q}$ is transformed back to the $x-y$ coordinate system and thus $\psi$ and $\gamma$ are computed as follows:

$$
\begin{gathered}
\Psi=\sqrt{\Psi_{x}^{2}+\Psi_{y}^{2}} \\
\gamma=\arctan \left(\frac{\Psi_{y}}{\Psi_{x}}\right)
\end{gathered}
$$

Fig. 2 shows the block diagram of the predictive controller. According to Fig. 2, a load-angle controller is used (which is in default a PI controller) in order to synthesize the load-angle increment signal $(\Delta \delta)$ based on the torqueerror signal $\left(m_{\text {err }}\right) . \Delta \delta$ is added to the position of the stator flux vector in the $x-y$ coordinate system $(\gamma)$, which results in the stator flux vector position reference signal $\left(\gamma_{\text {ref }}\right) \cdot \gamma_{\text {ref }}$ is fed to the voltage vector calculator along with the stator flux amplitude reference signal $\left(\psi_{\text {ref }}\right)$.

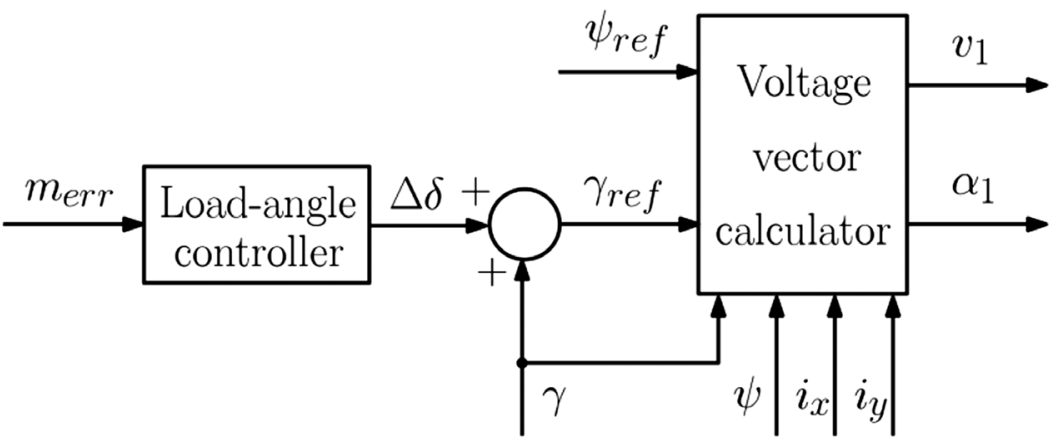

Fig. 2. The predictive controller (Swierczynski and Kazmierkowski, 2002; Swierczynski et al., 2002; Vajsz et al., 2017)

The voltage vector calculator uses the following equations in order to compute the stator voltage vector reference:

$$
\begin{gathered}
V_{x, \text { ref }}=\frac{\Psi_{\text {ref }} \cos \gamma_{\text {ref }}-\Psi \cos \gamma}{T_{s}}+\mathrm{Ri}_{\mathrm{x}} \\
V_{y, \text { ref }}=\frac{\Psi_{\text {ref }} \sin \gamma_{\text {ref }}-\Psi \sin \gamma}{T_{s}}+\mathrm{Ri}_{\mathrm{y}} \\
v_{1}=\sqrt{v_{x, \text { ref }}^{2}+v_{y, \text { ref }}^{2}} \\
\alpha_{1}=\arctan \left(\frac{v_{y, \text { ref }}}{v_{x, \text { ref }}}\right),
\end{gathered}
$$

where $v_{\mathrm{x}, \mathrm{ref}}$ and $v_{\mathrm{y}, \mathrm{ref}}$ are the real-axis and the imaginary-axis components of the stator voltage vector reference in the $x-y$ coordinate-system, $R$ is the stator resistance and $T_{\mathrm{s}}$ is the torque-control sample time.

Fig. 3 shows the basic principle of SVM. In this article, a two-level, three-phase voltage-source inverter is assumed. The voltage vectors belonging to the switching states of the inverter are marked with green in Fig. 3 $(\bar{v}(1), \ldots, \bar{v}(6)$; the two zero vectors are denoted as $\bar{v}(0)$ for better visibility). The non-zero vectors are called the active vectors. These are

$$
\overline{\mathrm{v}}(k)=\frac{2}{3} V_{\mathrm{DC}} \mathrm{e}^{\mathrm{j}(k-1) 60^{\circ}},
$$


where $v_{\mathrm{DC}}$ is the DC-bus voltage and $k=1,2, \ldots, 6$. In the case of SVM, the stator voltage vector reference $\left(\overline{\mathrm{v}}_{1}(\mathrm{n})\right.$ in Fig. 3) is synthesized as the linear combination of the neighbouring vectors of the current sector (the sector numbers are denoted with red in Fig. 3; their interpretation is different from that of the sector numbers of the DTC). The two zero vectors are neighbouring vectors to all of the sectors.

For example, if the stator voltage vector reference resides in the first sector like in Fig. 3, the following duty cycles should be applied on $\overline{\mathrm{v}}(1), \overline{\mathrm{v}}(2)$ and $\overline{\mathrm{v}}(0)$ :

$$
\begin{gathered}
d_{1}=\frac{\sqrt{3} \mathrm{v}_{1}(n)}{v_{\mathrm{DC}}} \sin \left(60^{\circ}-\alpha_{1}(n)\right) \\
d_{2}=\frac{\sqrt{3} \mathrm{v}_{1}(n)}{V_{\mathrm{DC}}} \sin \alpha_{1}(n) \\
d_{0}=1-d_{1}-d_{2},
\end{gathered}
$$

where

$d_{1}, d_{2}$ and $d_{0}$ are the duty cycles of the $\overline{\mathrm{v}}(1), \overline{\mathrm{v}}(2)$ and $\overline{\mathrm{v}}(0)$ voltage vectors, respectively; $\mathrm{v}_{1}(n)$ is the amplitude of the stator voltage vector reference in the $n$th sampling period and $\alpha_{1}(n)$ is the angle of the stator voltage vector reference expressed in the $x-y$ coordinate system in the $n$th sampling period.

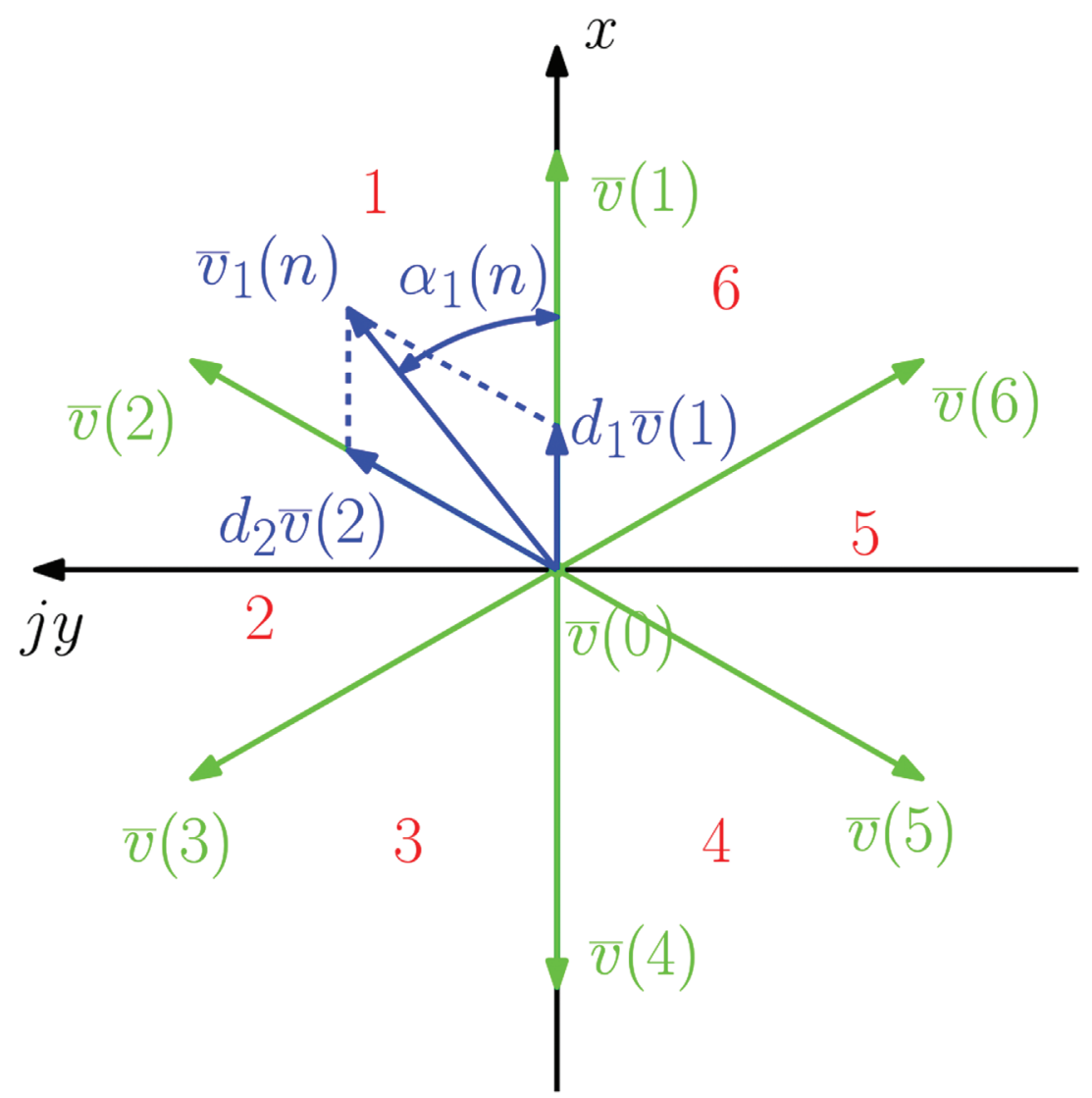

Fig. 3. Space vector modulation (Vajsz et al., 2017) 
The DTC-SVM is used in the case of other motor types as well. Detailed descriptions of the DTC-SVM and SVM itself can be read in Swierczynski and Kazmierkowski (2002), Swierczynski et al. (2002), Vajsz et al. (2017), Blaabjerg et al. (2005), Buja and Kazmierkowski (2004), Foo and Zhang (2016), Grabowski et al. (2000), Klimkowski (2016), Malinowski et al. (2004), Malinowski et al. (2003), Orłowska-Kowalska and Dybkowski (2016), Pinto et al. (2000), Vajsz and Számel (2018), Zelechowski et al. (2005) and Zhang and Foo (2019).

Based on the short description given in this section, it can be concluded that the DTC-SVM is a complex and parameter-sensitive method for controlling the electromagnetic torque of synchronous reluctance motor drives because the exact position of the rotor is required by the estimator and the method requires all the motor parameters in order to accomplish the control task.

\section{Simulation Results}

Simulation was carried out for an industrial synchronous reluctance motor in the Matlab-Simulink environment, using the parameters in Table 1. The investigations were carried out for the normal operation region only. The stator flux amplitude reference was set to its nominal value. The torque-control sample time varied during the investigations in order to make a comparison. The process consisted of acceleration for up to $4000 \mathrm{rpm}$; a loadtorque step of $3 \mathrm{Nm}$; a reversal, which is followed by the elimination of the $3 \mathrm{Nm}$ load torque, and finally a stopping command. It must be noted that the simulation parameters and the simulated process are the same as in Vajsz et al. (2019). This means that the results will be comparable with those of the DTC and the HCVC (phase current-based hysteresis current vector control) presented in Vajsz et al. (2019).

Table 1. Simulation parameters

\begin{tabular}{lc}
\hline Motor nominal speed & $4000 \mathrm{rpm}$ \\
Motor number of pole pairs & 2 \\
Motor nominal torque & $3.1 \mathrm{Nm}$ \\
Motor nominal current & $6 \mathrm{~A}_{\mathrm{RMS}}$ \\
$R$ & $1.2 \Omega$ \\
$L_{d}$ & $43.8 \mathrm{mH}$ \\
$L_{q}$ & $15.3 \mathrm{mH}$ \\
DC-bus voltage & $540 \mathrm{~V}$ \\
Total moment of inertia & $3.8 \mathrm{kgcm}$ \\
Speed-control sample time & $200 \mu \mathrm{s}$ \\
Simulation sample time & $1 \mu \mathrm{s}$ \\
\hline
\end{tabular}

Figs. 4-7 show the process for the DTC-SVM with a 100- $\mu$ s torque-control sample time and a 10-kHz PWM frequency. According to Fig. 4, the DTC-SVM is capable of realizing an excellent closed-loop speed-control performance, which is essential in the case of motion control applications.

Based on Figs. 5-7, the DTC-SVM provides excellent results in means of torque, flux and current ripples with a 100- $\mu$ s torque-control sample time and PWM period time already. In addition, it can be concluded that the method is capable of a good torque-control dynamic performance and the tracking of the torque reference is error free in the steady state. As it can be seen in Figure 6, the DTC-SVM controls the amplitude of the stator flux vector in a closed-loop manner. In addition, the flux ripples are of a significantly smaller amount than in the case of the DTC and the HCVC even with a 20- $\mu$ s torque-control sample time (Vajsz et al., 2019).

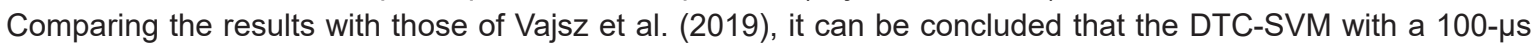

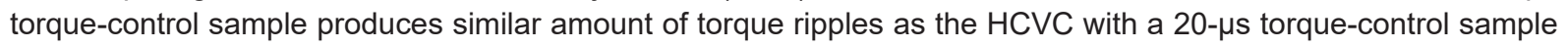
in Vajsz et al. (2019). This means that the DTC-SVM is suitable for synchronous reluctance motor motion control applications and the method does not require a relatively high sampling frequency in order to achieve this (10 kHz is enough, whereas in the case of the HCVC - based on Vajsz et al. (2019) - approximately $50 \mathrm{kHz}$ is required).

Figs. 8 and 9 show the torque and the current for the DTC-SVM with a 50- $\mu$ s torque-control sample time and a 20-kHz PWM frequency. Based on these figures and Figs. 8 and 12 of Vajsz et al. (2019), it can be concluded 
that the DTC-SVM with a 50- $\mu$ s torque-control sample time provides the best results out of all investigated cases in means of torque and current ripples, surpassing even the HCVC with a $20-\mu$ s torque-control sample time.

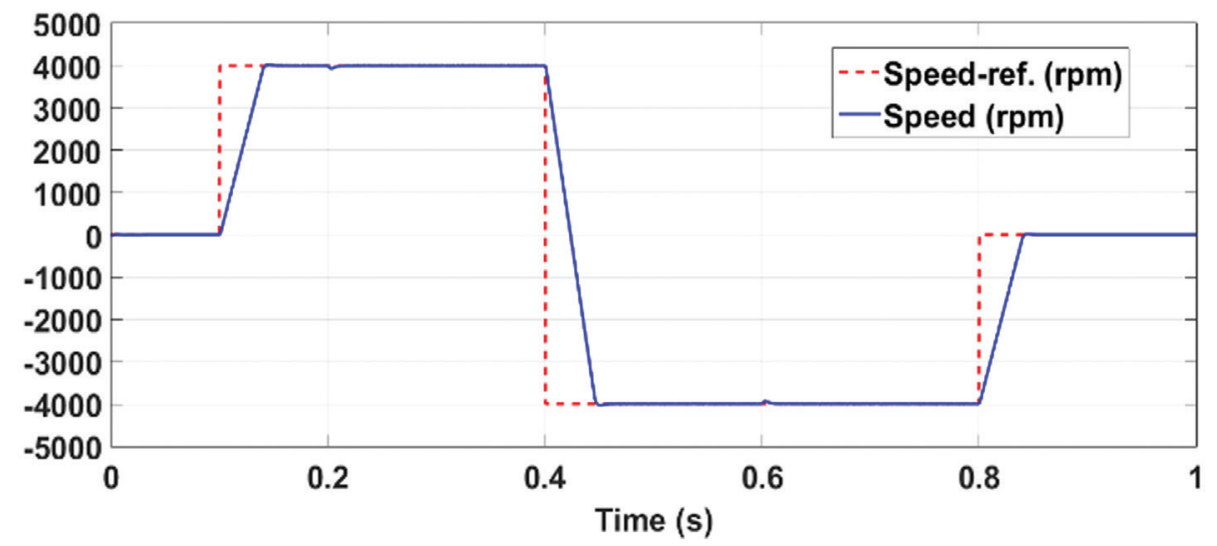

Fig. 4. The speed reference and the speed in the case of the DTC-SVM with a $100-\mu$ s torque-control sample time

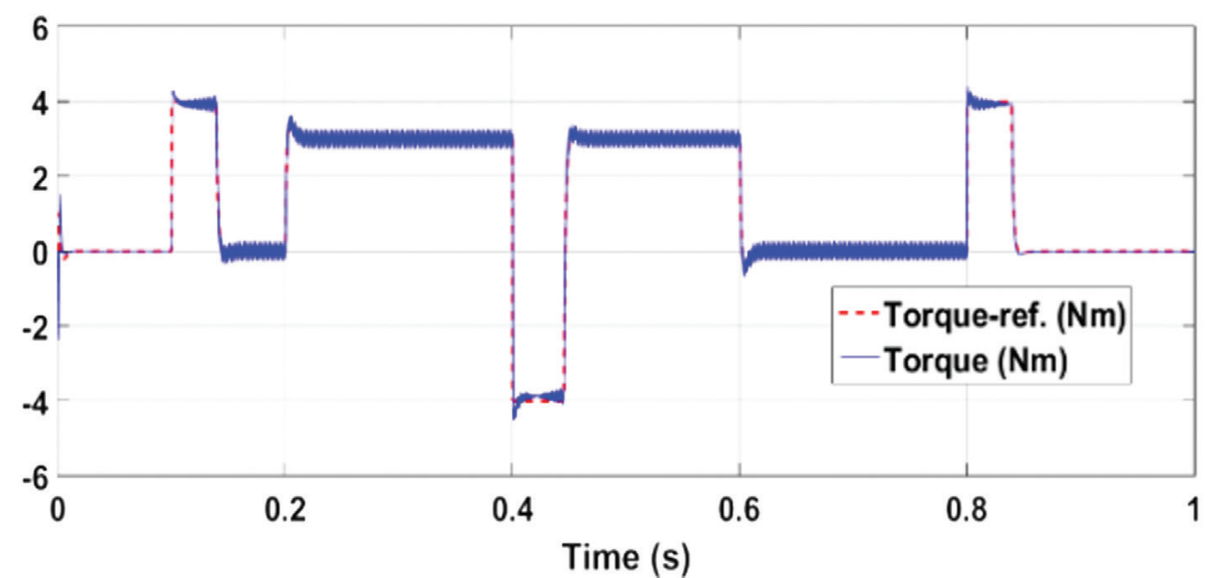

Fig. 5. The torque reference and the electromagnetic torque in the case of the DTC-SVM with a 100- $\mu$ s torque-control sample time

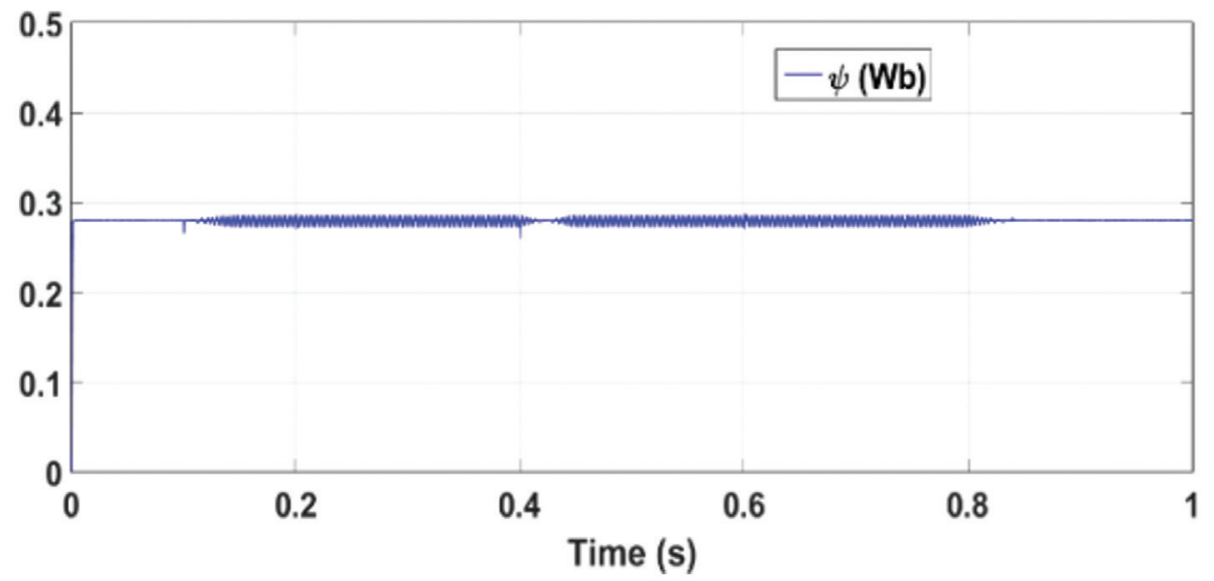

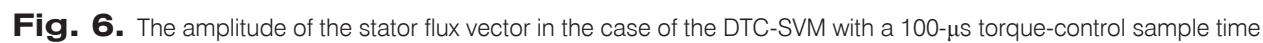




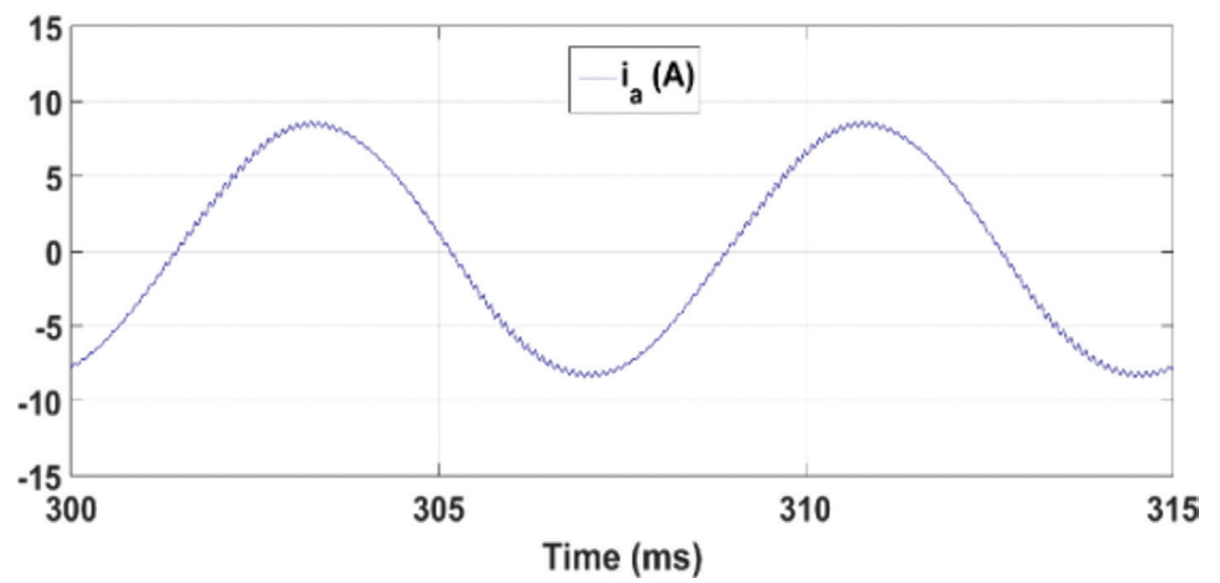

Fig. 7. A stator phase current in the steady state in the case of the DTC-SVM with a 100- $\mu$ s torque-control sample time

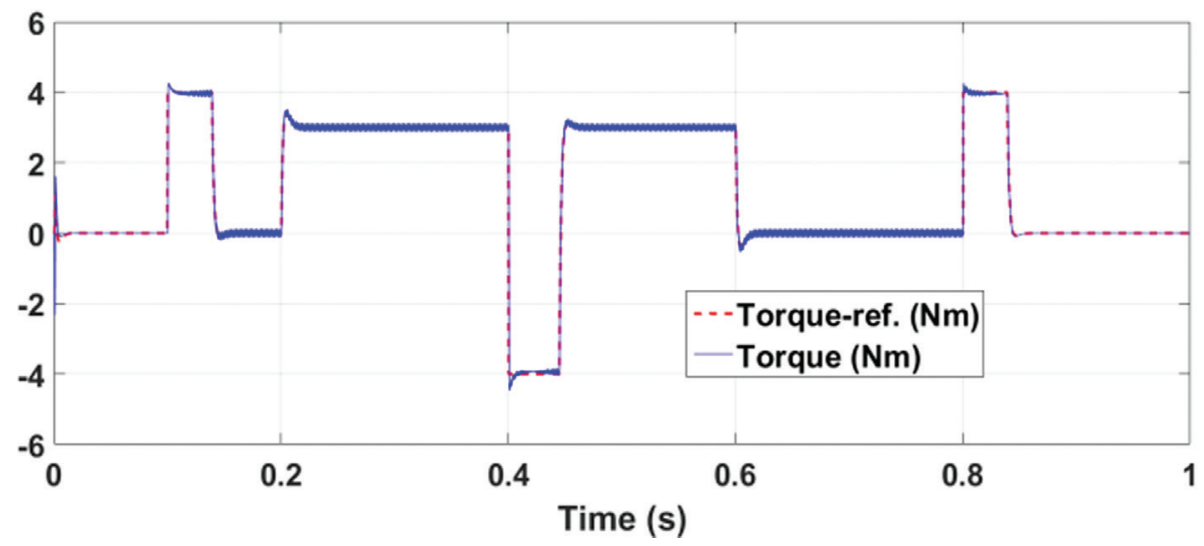

Fig. 8. The torque reference and the electromagnetic torque in the case of the DTC-SVM with a $50-\mu$ s torque-control sample time

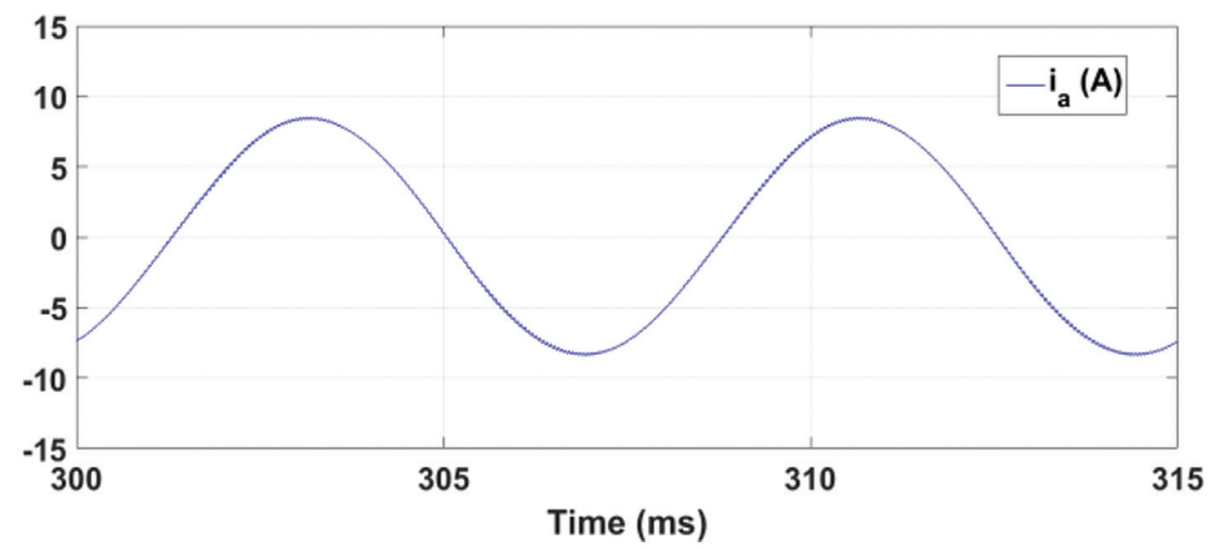

Fig. 9. A stator phase current in the steady state in the case of the DTC-SVM with a 50- $\mu$ s torque-control sample time

Figs. 10-15 show an FFT analysis of the torque ripples for the DTC-SVM, the DTC and the HCVC. The load torque was $3 \mathrm{Nm}$, and the speed was $4000 \mathrm{rpm}$ during the FFT investigations. Based on these figures, it can be 
concluded that the DTC and the HCVC have a rather "dispersed" spectrum, while the DTC-SVM has a rather "regular" spectrum. This means that in the former cases, the ripples are distributed in the frequency spectrum, while in the latter case, the ripples are concentrated on dedicated frequencies and the rest of the spectrum contains harmonics with negligible amplitude.

According to Figs. 10-15, the HCVC with a $20-\mu$ s torque-control sample time and the DTC-SVM with a $50-\mu s$ torque-control sample time provide the best results in means of torque spectrum: in the case of the HCVC, the torque harmonics are of minimal amplitude, which are roughly equally distributed in the frequency spectrum, while in the case of the DTC-SVM, they are concentrated on dedicated frequencies. It is application dependent which method can be considered better, but both of them fulfil the requirements of most motion control applications.

The second best is the DTC-SVM with a 100- $\mu$ s torque-control sample time and the DTC with a $20-\mu$ s torquecontrol sample time. The situation is similar: it is application dependent which one can be considered better. They are recommended in the case of less-precise motion control applications.

The HCVC and the DTC with a 50- $\mu$ s torque-control sample time are unsuitable for most motion control applications because the torque harmonics are of significant amplitude and the dominant harmonics are located in the low-frequency range $(<10 \mathrm{kHz})$ where the mechanics usually has a high gain factor.

In order to select the best-suited method for synchronous reluctance motor motion control applications, there are other important aspects that must be taken into account. Based on Vajsz et al. (2019), the main advantage of the HCVC over the other examined methods is that it is a simple method, the control system is easy to tune (only hysteresis controllers are being used) and the method does not require much computation. However, based on Figs. 12 and 13 and Vajsz et al. (2019), its main disadvantage is that it requires a relatively high sampling frequency in order to give good results (approximately $50 \mathrm{kHz}$ ).

The main drawback of a relatively high torque-control sampling frequency is that it results in a relatively high switching frequency. The $50 \mathrm{kHz}$ switching frequency is difficult to realize with nowadays conventional semiconductor devices. However, the modern silicon carbide and gallium nitride semiconductor devices are expected to make such high switching frequencies easily achievable (Tarczewski et al., 2018; Stubenrauch et al., 2017).

In drive systems where the realization of a high torque-control sampling frequency is an issue, the utilization of the DTC-SVM is recommended. The DTC-SVM has a far more complex control system and requires much more computation, but it does not require a high sampling frequency in order to give good results $(10-20 \mathrm{kHz}$ is sufficient). According to Figs. 10 and 11 and Vajsz et al. (2019), the DTC is recommended in applications where a simple, robust and less parameter-sensitive solution is necessary and a lower precision level is acceptable.

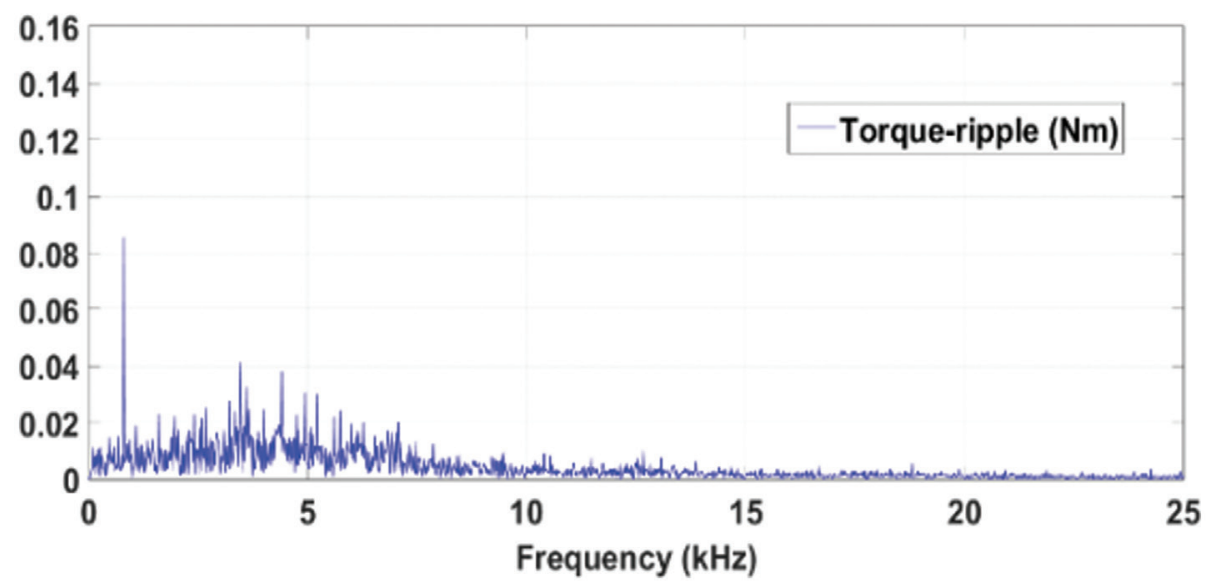

Fig. 10. Torque-ripple FFT in the case of the DTC with a $20-\mu$ s torque-control sample time

All in all, it can be concluded that the hysteresis-type methods analysed in this article (namely, the HCVC and the DTC) are more robust to parameter changes, their controllers are easier to tune and they have a relatively simple control system. These advantages come along with the price of increased torque ripples compared to a conventional-type torque-control method like the DTC-SVM at the same torque-control sampling frequency. The DTC-SVM produces less torque ripples at the same torque-control sampling frequency, but it is more parameter 
sensitive; has more complex controllers, which are more difficult to tune, and requires much more computation. However, the DTC-SVM does not require a relatively high torque-control sampling frequency. The choice should be based on the requirements of the application and the user.

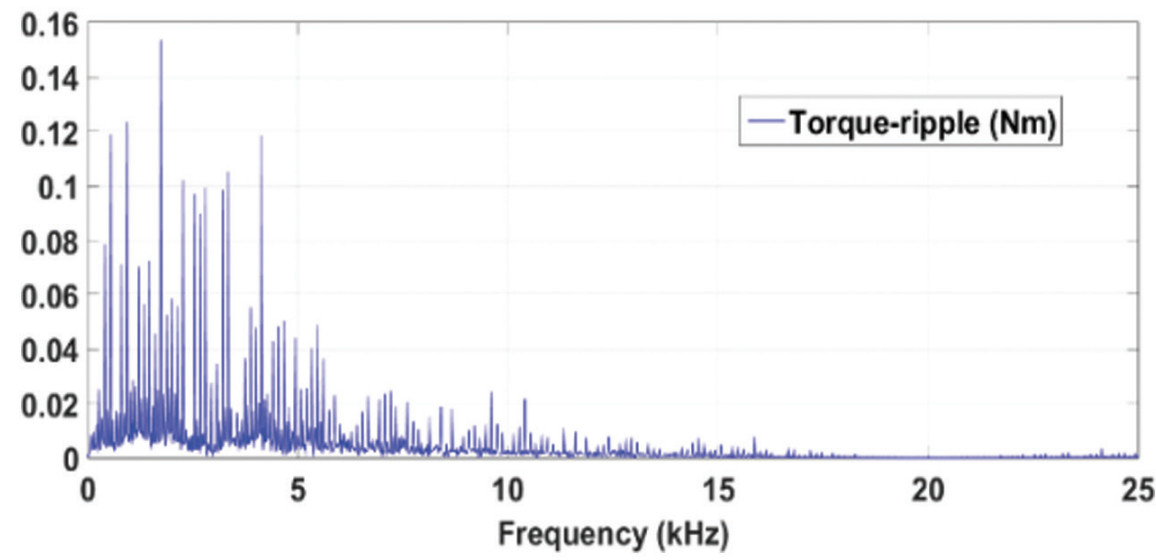

Fig. 11. Torque-ripple FFT in the case of the DTC with a 50-ps torque-control sample time

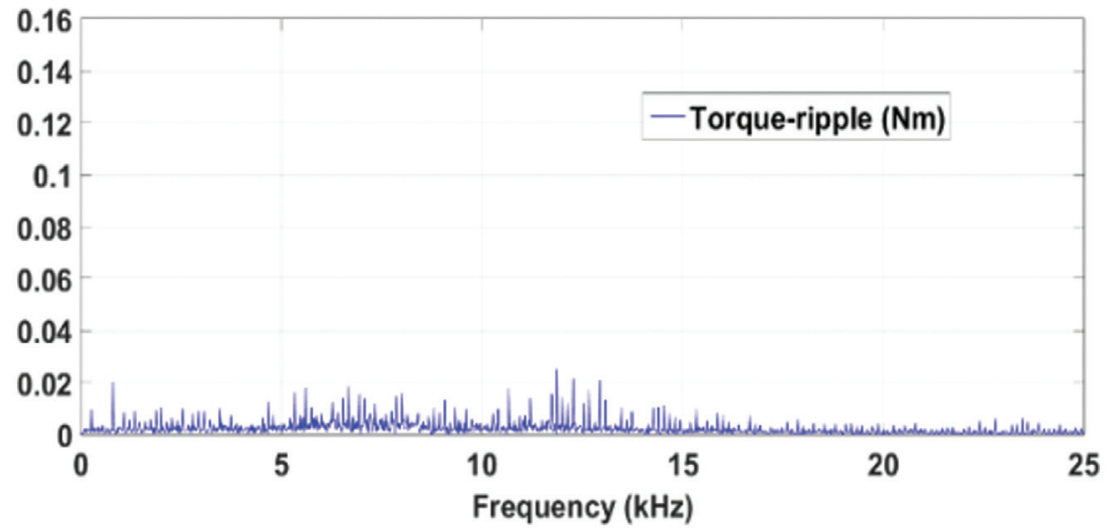

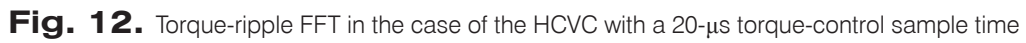

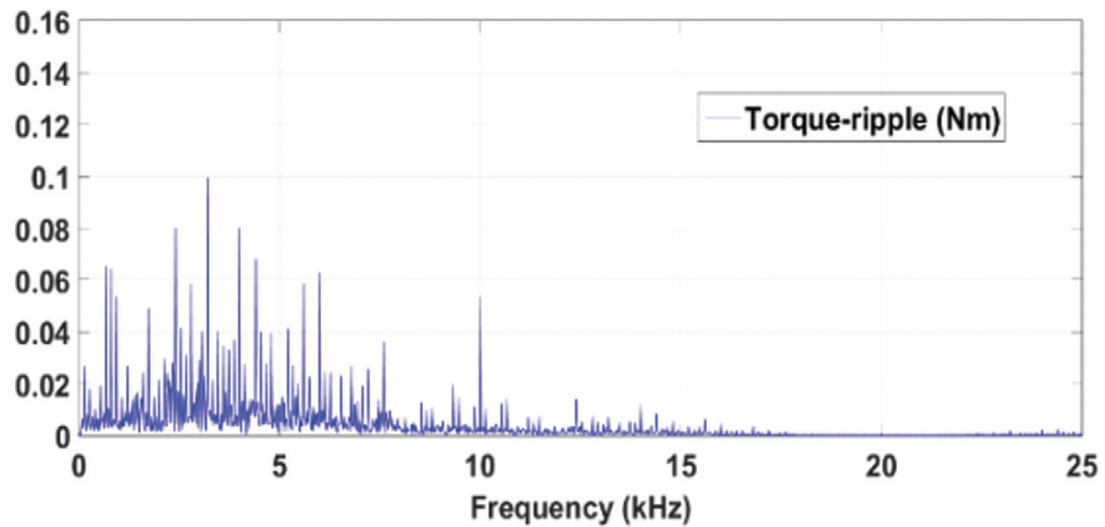

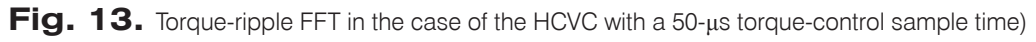




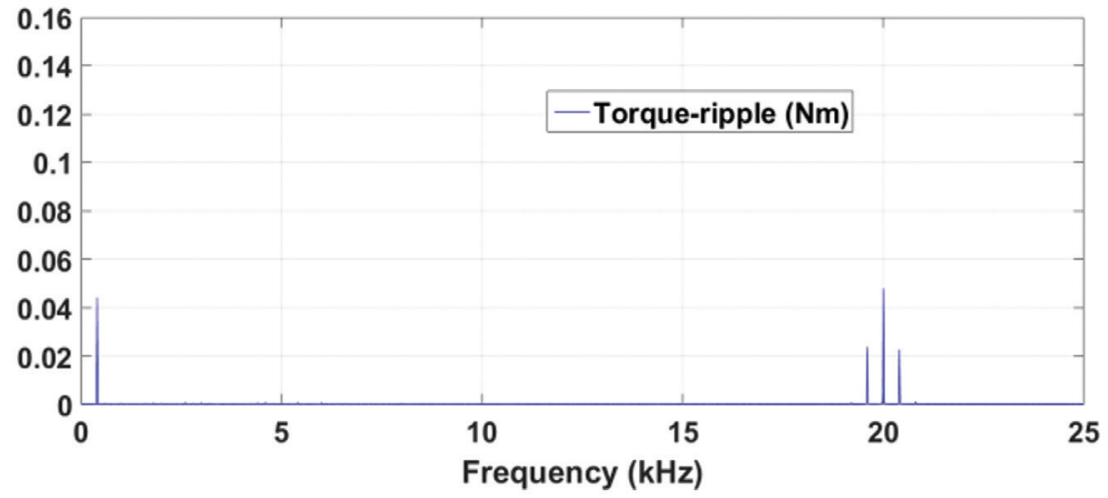

Fig. 14. Torque-ripple FFT in the case of the DTC-SVM with a 50- $\mu$ s torque-control sample time

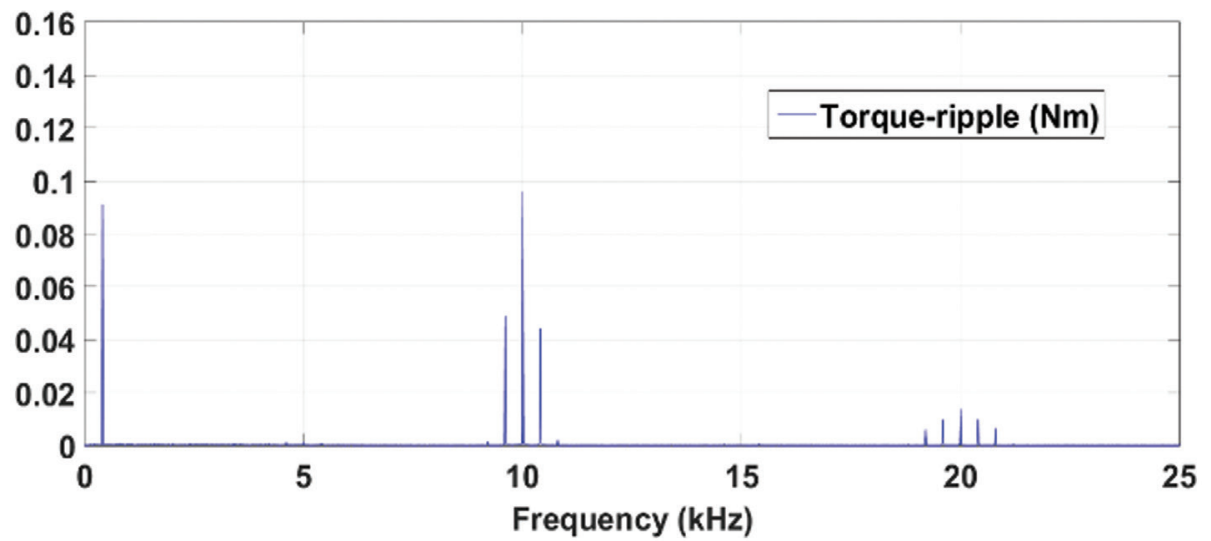

Fig. 15. Torque-ripple FFT in the case of the DTC-SVM with a $100-\mu$ s torque-control sample time

\section{Conclusions}

In this article, DTC-SVM has been analysed for synchronous reluctance motor motion control applications. An FFT analysis has been carried out for the DTC-SVM, the DTC and the HCVC with different torque-control sample times, and it has been concluded that the HCVC with a $20-\mu$ s torque-control sample time and the DTC-SVM with a $50-\mu s$ torque-control sample time give the best results from the point of view of the torque ripples generated. Therefore, these are recommended for motion control applications requiring higher precision levels, while the DTC-SVM with a $100-\mu$ s torque-control sample time and the DTC with a $20-\mu$ s torque-control sample time are recommended in the case of less-precise motion control applications. The other important aspects that have to be considered for the selection of the best-suited method have been summarized, and the fields of applications for the three methods have also been given.

\section{References}

Blaabjerg, F., Kazmierkowski, M. P., Zelecehowski, M., Swierczynski, D. and Kolomyjski, W. (2005). Design and comparison direct torque control techniques for induction motors. In: 2005 European Conference on Power Electronics and Applications, pp. 9 pp.-P.9. doi: 10.1109/ EPE.2005.219515

Buja, G. S. and Kazmierkowski, M. P. (2004). Direct Torque Control of PWM Inverter-Fed AC Motors - A Survey. IEEE Transactions on Industrial 
Electronics, 51(4), pp. 744-757. doi: 10.1109/ TIE.2004.831717

Foo, G. H. B. and Zhang, X. (2016). Robust Constant Switching Frequency-Based Field-Weakening Algorithm for Direct Torque Controlled Reluctance Synchronous Motors. IEEE Transactions on Industrial Informatics, 12(4), pp. 1462-1473. doi: 10.1109/TII.2016.2585646

Grabowski, P. Z., Kazmierkowski, M. P., Bose, B. K. and Blaabjerg, F. (2000). A Simple DirectTorque Neuro-Fuzzy Control of PWM-InverterFed Induction Motor Drive. IEEE Transactions on Industrial Electronics, 47(4), pp. 863-870. doi: 10.1109/41.857966

Klimkowski, K. (2016). An Artificial Neural Networks Approach to Stator Current Sensor Faults Detection for DTC-SVM Structure. Power Electronics and Drives, 36(1), pp. 127-138. doi: 10.5277/ PED160109

Malinowski, M., Jasinski, M. and Kazmierkowski, M. P. (2004). Simple direct power control of three-phase PWM rectifier using space-vector modulation (DPC-SVM). IEEE Transactions on Industrial Electronics, 51(2), pp. 447-454. doi: 10.1109/ TIE.2004.825278

Malinowski, M., Kazmierkowski, M. P. and Trzynadlowski, A. M. (2003). A Comparative Study of Control Techniques for PWM Rectifiers in AC Adjustable Speed Drives. IEEE Transactions on Power Electronics, 18(6), pp. 1390-1396. doi: 10.1109/ TPEL.2003.818871

Orłowska-Kowalska, T. and Dybkowski, M. (2016). Industrial Drive Systems. Current State and Development Trends. Power Electronics and Drives, 36(1), pp. 5-25. doi: 10.5277/PED160101

Pinto, J. O., Bose, B. K., Da Silva, L. B. and Kazmierkowski, M. P. (2000). A Neural-NetworkBased Space-Vector PWM Controller for Voltage-Fed Inverter Induction Motor Drive. IEEE Transactions on Industry Applications, 36(6), pp. 1628-1636. doi: 10.1109/28.887215

Stubenrauch, F., Wittmann, J., Kiermayer, A., Seliger, N., Hagl, R., Schmitt-Landsiedel, D. and Kennel, R. (2017). FPGA-based high dynamic servo drive control with a $200 \mathrm{kHz}$ Gallium Nitride inverter. In: 2017 19th European Conference on Power Electronics and Applications (EPE'17 ECCE Europe), Warsaw, pp. P.1-P.10. doi: 10.23919/ EPE17ECCEEurope.2017.8098997
Swierczynski, D. and Kazmierkowski, M. P. (2002). Direct torque control of permanent magnet synchronous motor (PMSM) using space vector modulation (DTC-SVM)-simulation and experimental results. In: IEEE 2002 28th Annual Conference of the Industrial Electronics Society. IECON 02, pp. 751-755. doi: 10.1109/IECON.2002.1187601

Swierczynski, D., Kazmierkowski, M. P. and Blaabjerg, F. (2002). DSP based direct torque control of permanent magnet synchronous motor (PMSM) using space vector modulation (DTC-SVM). In: Proceedings of the 2002 IEEE International Symposium on Industrial Electronics, pp. 723-727. doi:10.1109/ISIE.2002.1025821

Vajsz, T. and Számel, L., (2018). Overload-Capability Analysis of PMSM Servo- and Robot-Drives Using DTC-SVM Methods: Part 1. In: 2018 IEEE 18th International Power Electronics and Motion Control Conference (PEMC), Budapest, pp. 730-736. doi: 10.1109/EPEPEMC.2018.8521929

Vajsz, T., Számel, L. and Handler, Á. (2019). An Investigation of Direct Torque Control and Hysteresis Current Vector Control for Motion Control Synchronous Reluctance Motor Applications. Power Electronics and Drives, 39(1), pp. 1-12.

Vajsz, T., Számel, L. and Rácz, G. (2017). A Novel Modified DTC-SVM Method with Better Overloadcapability for Permanent Magnet Synchronous Motor Servo Drives. Periodica Polytechnica Electrical Engineering and Computer Science, 61(3), pp. 253-263. doi: 10.3311/PPee.10428

Zelechowski, M., Kazmierkowski, M. P. and Blaabjerg, F. (2005). Controller design for direct torque controlled space vector modulated (DTC-SVM) induction motor drives. In: Proceedings of the IEEE International Symposium on Industrial Electronics (ISIE 2005), pp. 951-956. doi: 10.1109/ ISIE.2005.1529052

Tarczewski, T., Skiwski, M., Grzesiak, L. M. and Zielinski, M. (2018). PMSM Servo-Drive Fed by SiC MOSFETs Based VSI. Power Electronics and Drives, 38(1), pp. 35-45. doi: 10.2478/pead-20180001

Zhang, X. and Foo, G. H. B. (2019). Overmodulation of Constant-Switching-Frequency-Based DTC for Reluctance Synchronous Motors Incorporating Field-Weakening Operation. IEEE Transactions on Industrial Electronics, 66(1), pp. 37-47. doi: 10.1109/TIE.2018.2826478 